\title{
Steroids and miRNAs in assessment of ovarian tissue damage following cryopreservation
}

\author{
Nadia Islam, Ugwoke Sunday Paul, Rana Alhamdan, Juan Hernandez-Medrano, Bruce K Campbell, Peter Marsters \\ and Walid E Maalouf
}

Division of Child Health, Obstetrics and Gynaecology, School of Medicine, University of Nottingham, Nottingham, UK

Correspondence should be addressed to W E Maalouf: walid.maalouf@nottingham.ac.uk

\begin{abstract}
Ovarian cortical tissue cryopreservation is a relatively novel approach to preserving fertility in women diagnosed with cancer. However, the effects of freezing-thawing are not fully understood, mainly due to the lack of suitable methods to assess tissue's survival after thawing. Disparities in steroid production have been associated with ovarian failure by disrupting folliculogenesis, ovulation and oocyte apoptosis. Moreover, specific miRNAs, identified in human ovarian follicles, are thought to play a fundamental role in folliculogenesis. In this study, we investigated the possible interplay between the ovarian steroidal production and miRNA expression patterns in spent culture media, as potential non-invasive markers for ovarian tissue damage after cryopreservation. Cryopreservation of ovarian cortical tissue decreased $(P<0.05)$ both steroid production (oestradiol and progesterone) and expression of miRNA-193b and 320A in spent culture media over 5 days; however, expression of miRNA-24 increased $(P<0.05)$. The number of primordial follicles was also reduced $(P<0.05)$ in fresh-cultured and cryopreserved-cultured cortical tissues when compared with fresh tissues. Downregulation of miRNA-193b and miRNA$320 \mathrm{~A}$ together with upregulation of miRNA-24 could have a synergistic role in cell apoptosis, and consequently leading to reduced oestradiol and progesterone production. Thus, there appears to be an interplay between these miRNAs, ovarian steroid production and cell damage, which can be further explored as novel non-invasive markers of cell damage following cryopreservation.
\end{abstract}

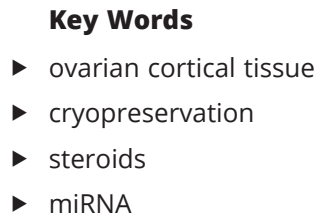

Journal of Molecular Endocrinology (2019) 62, 207-216

\section{Introduction}

Cryopreservation of ovarian cortical tissue is a novel approach to preserving fertility in women who are at risk of infertility, particularly in younger oncology patients (Abir et al. 2016). However, the effects of freeze-thawing are not fully understood, mainly due to the lack of suitable methods to assess tissue's survival after thawing. Among the cryopreservation techniques, vitrification of oocytes and embryos is an effective method resulting in high survival rate and pregnancy outcomes (Al-Azawi et al.
2013). However, for ovarian cortical tissue, slow freezing is the method that has provided best results. More than 130 live births have been reported following transplantation of slow-frozen cryopreserved ovarian cortical tissue, showing high primordial and primary follicle pool survival post transplant (Amorim et al. 2011, Donnez et al. 2015, Abir et al. 2017, Donnez \& Dolmans 2017).

A succession of organisational and functional processes take place in ovary throughout the female's 
life, indispensable for maintaining reproductive potential (Baerwald et al. 2012). For example, endocrine signals such as patterns of gonadotropins production and release (follicle-stimulating hormone (FSH), luteinising hormone (LH)) which modulate the production and release of sex steroidal hormones oestradiol, progesterone and androstenedione. These ovarian steroids are key local intra-ovarian factors involved in the regulation of folliculogenesis (Zumbado et al. 2010). Changes in the above endocrine network have been linked to premature ovarian failure (POF) due to disruption of folliculogenesis, ovulation failure and loss of oocytes via apoptosis (Yang et al. 2012).

miRNAs are evolutionarily conserved, single-stranded, non-coding RNA molecules, consist of 18-22 nucleotides. They are important intercellular signalling molecules, known to have major roles in post-transcriptional gene regulation (Weber et al. 2010, Cortez et al. 2011) and protein synthesis (Mukherji et al. 2011). In many cells, specific miRNAs are expressed differentially in disease states compared to normal tissue. Recent reports have identified miRNAs in human ovarian follicles that may be able to modulate reproduction (Houbaviy et al. 2003).

Over 200 miRNAs have been reported in human follicular fluid and other body fluids such as serum, urine and saliva (Rayner \& Hennessy 2013, Xu et al. 2013). Due to the nature of these miRNAs and their ability to have an effect on multiple target sites, it is difficult to determine the specific role of a particular miRNA. Using bioinformatics analysis, Sang et al. (2013) studied the miRNA expression in granulosa cells and follicular fluid and its correlation with endocrine, reproductive and metabolic functions. They identified miRNA-320 and miRNA-24 as regulators of oestradiol production, whereas miRNA-24 and miRNA193b regulate progesterone. MiRNA-24 was found to decrease oestradiol secretion while miRNA-320 was found to increase it (Sang et al. 2013). The lack of tight regulation of these processes by miRNAs can cause disruptions and prevent certain stages of development occurring within the correct time frame during folliculogenesis, and it can lead to abnormalities in oocyte development. It is also thought to have an effect on oocyte-granulosa cell relationships and in turn could have detrimental effects on normal recruitment and development of follicles (Toloubeydokhti et al. 2008).

Rotatory cell culture system (RCCS) has been used in cancer cell lines and stem cell culture because it allows cell co-culture and high nutrient transfer with low shear force (Morabito et al. 2015, Snyder et al. 2016). This vessel simulates the 3D environment in which tissue normally develops and functions (Barrila et al. 2010). Previous work from our laboratory involving ovine ovarian cortical tissue, cultured in the RCCS for 7 days showed significant decrease in the primordial follicles and increase in the number of primary and secondary follicles. Telfer and colleagues in 2008 reported successful antrum formation and oocyte growth within ovarian cortical tissues using a two-step culture system of 6 days with the addition of activin. However, there was significant reduction in the number of primordial and primary follicles between at the time of cortical tissue collection and after 6 days of culture (Telfer et al. 2008).

In this experiment, we investigated the possible interplay between steroid production and miRNAs' expression pattern that could help in the assessment of tissue damage post freeze-thaw cycles. We studied steroid production and miRNAs' expression to evaluate the tissue functionality following cryopreservation of ovarian cortical tissue using a controlled rate cryopreservation protocol. Expression of miRNA-193b, 24, 320A and oestradiol, progesterone androstenedione production was evaluated in ovarian cortical tissue subjected or not to cryopreservation followed by 5 days culture in a RCCS system. In this study, sheep was used as model species due to their well described pre-antral follicular dynamics and similarities to human reproductive tissues (Campbell et al. 2012)

\section{Materials and methods}

All materials and media were obtained from Sigma-Aldrich Ltd, unless stated otherwise.

\section{Collection of ovaries and preparation of ovarian cortical tissue}

Sheep ovaries were collected from a local abattoir, transported to the laboratory and kept in pre-warmed dissection media (20 mM HEPES in Medium 199 supplemented with $1 \%$ penicillin/streptomycin, $1 \%$ fungizone (amphotericin B-250 $\mu \mathrm{g} / \mathrm{mL}$ ))at $37^{\circ} \mathrm{C}$ until use.

Ovarian cortical tissues of approximately $5 \mathrm{~mm}^{2}$ in area and $1 \mathrm{~mm}$ in thickness were collected using a sterile Rosenberg skin grafting knife (4 Med Ltd., Sderot, Israel). After collection, cortical tissues were randomly assigned in to three groups: fresh $(n=20)$, fresh-cultured $(n=20)$ and cryopreserved-cultured $(n=20)$. Fresh cortical tissues $(n=20)$ were immediately fixed in $4 \%$ paraformaldehyde (PFA) for histological evaluation using haematoxyslin \& eosin (H\&E) staining. The remaining cortical tissues were 
either cryopreserved $(n=20)$ or not $(n=20)$, followed by a 5-day RCCS culture, after which tissues were fixed and stained for histological evaluation. A detailed schematic diagram describing the experimental units has been shown in Fig. 1.

\section{Ovarian cortical tissue culture}

Ovarian cortical tissues were placed into RCCS vessel (freshcultured and cryopreserved-cultured groups) through the main lock port using forceps. The vessel was tilted at $45^{\circ}$ to ensure the ovarian tissues remain immersed in culture media. Vessels containing the tissues were filled with $10 \mathrm{~mL}$ of granulosa cell (GC) culture media (McCoy's 5A with sodium bicarbonate PLUS containing $1 \mathrm{mg} / \mathrm{mL}$ bovine serum albumin (BSA), 1\% penicillin/streptomycin, 1.5\% L-glutamine, transferrin $(10 \mu \mathrm{g} / \mathrm{mL})$, Selenium $(4 \mathrm{ng} / \mathrm{mL})$, IGF-1 LR3 (10 ng/mL), insulin (10 ng/mL) and FSH (1 ng/ mL, NIAMDD-FSH-20)), mentioned by Campbell et al. (1996). The rotational speed was set to $10-14 \mathrm{rpm}$ according to the size of the tissue. Tissues were incubated at $37^{\circ} \mathrm{C}$ and $5 \% \mathrm{CO}_{2}$ for 5 days. Culture media $(6 \mathrm{~mL})$ was replaced with fresh media daily. Collected spent culture media was stored at $-20^{\circ} \mathrm{C}$ until used for steroid determination (oestradiol,

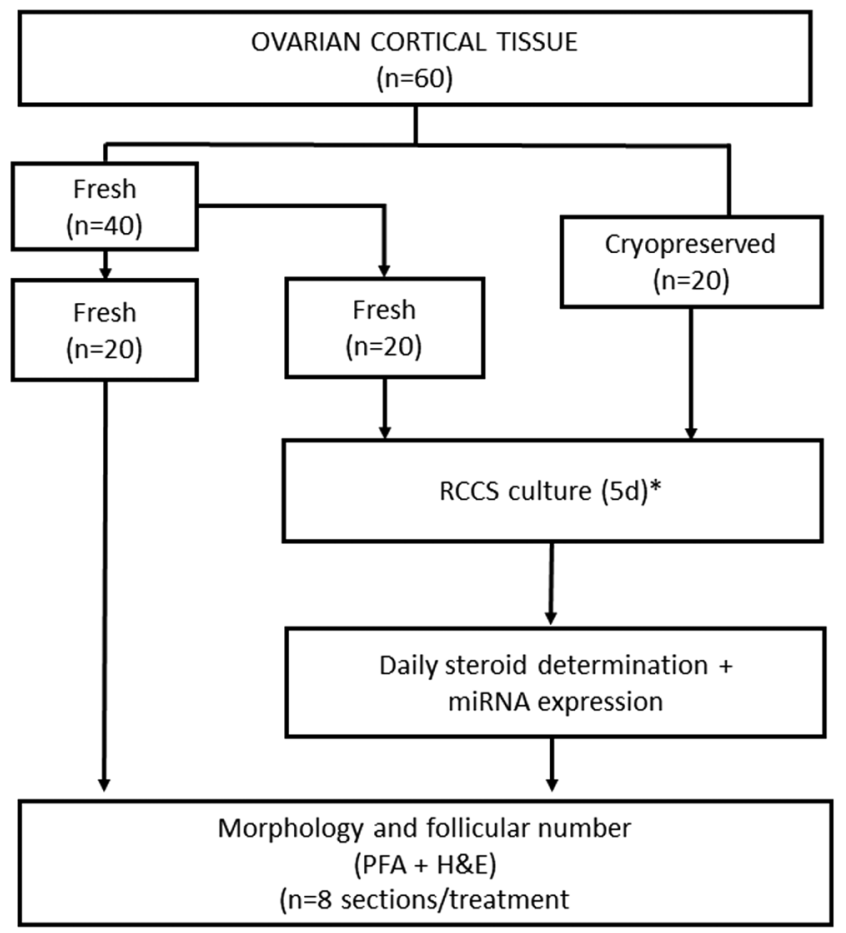

* 5 pieces / vessel and $n=4$ vessels / treatment)

Figure 1

Detailed schematic diagram of materials and methods describing the experimental units.

C) 2019 Society for Endocrinology Published by Bioscientifica Ltd. Printed in Great Britain progesterone and androstenedione) and miRNA (24, 193b and 320A) extraction.

\section{Slow freezing of ovarian cortical tissue}

Ovarian cortical tissues were cryopreserved following a controlled rate or slow freezing protocol, previously described by Gosden etal.(1994). Briefly, cortical tissues were first equilibrated on a roller mixer in $10 \mathrm{~mL}$ cryoprotectant (CPA) solution (1.5 M DMSO, 0.1 M sucrose and 10\% v/v foetal calf serum (FCS) in Leibovitz-L15 medium (L-15)) at $4^{\circ} \mathrm{C}$ for $30 \mathrm{~min}$ to allow maximum penetration of CPA. Equilibrated tissues were then transferred to a cryovial containing $1.8 \mathrm{~mL}$ CPA. Cryovials were transferred to a programmable freezer (Planer, Kryo 10 Series model 10-20, Planer Products Ltd, Sanbury-on-Thames, UK) held at $0^{\circ} \mathrm{C}$ (starting temperature). The freezing programme was then cooled down to $-9^{\circ} \mathrm{C}$ at a rate of $-2^{\circ} \mathrm{C} / \mathrm{min}$ and held at this temperature for manual seeding. Following this, the chamber temperature was brought down to $-40^{\circ} \mathrm{C}$ at a rate of $-0.3^{\circ} \mathrm{C} / \mathrm{min}$ and then to $-140^{\circ} \mathrm{C}$ at a rate of $-10^{\circ} \mathrm{C} / \mathrm{min}$. At the end of the programme $\left(-140^{\circ} \mathrm{C}\right)$, the samples were removed from the freezer and stored in liquid nitrogen at $-196^{\circ} \mathrm{C}$ (Gosden et al. 1994).

\section{Thawing of ovarian cortical tissue}

The cryovials were kept at a room temperature for 1 min and rapidly thawed at $37^{\circ} \mathrm{C}$ in a water bath for a maximum of $10 \mathrm{~min}$. After this, tissues were incubated in three different thawing media (TM) with decreasing concentrations of DMSO and sucrose in L15 medium: $\mathrm{TM}_{1}$ (1.0 M DMSO, $0.1 \mathrm{M}$ sucrose, 10\% FCS), $\mathrm{TM}_{2}(1 \mathrm{M}$ DMSO, $10 \%$ FCS $)$ and $\mathrm{TM}_{3}$ (10\% FCS only). Tissues were incubated for $10 \mathrm{~min}$ in each pre-warmed thawing solution $\left(37^{\circ} \mathrm{C}\right)$ on a roller mixer. After thawing, cortical tissue was cultured in RCCS for 5 days.

\section{Determination of oestradiol, progesterone and androstenedione concentration}

The concentration of oestradiol, progesterone and androstenedione produced by tissues in the spent culture media (fresh-cultured and cryopreserved-cultured groups) during culture in RCCS was determined using a competitive ELISA method, which has been optimised and validated in-house. To account for a possible effect of size differences in cortical sections incubated in the RCCS, steroid concentrations are presented as steroid production (ng) per volume of tissue $\left(\mathrm{mm}^{3}\right)$. 


\section{MiRNA extraction, cDNA synthesis and real-time PCR}

Total RNA in the spent culture media for cortical tissues (fresh-cultured and cryopreserved-cultured groups) were extracted using a Qiagen miRNeasy Mini Kit (Qiagen) according to manufacturer's instructions.

Total RNA concentration was determined using a NanoDrop spectrometer measuring the absorbance at $260 \mathrm{~nm}$. Purity was measured by calculating the 260/280 ratio. The TaqMan ${ }^{\mathrm{TM}}$ advanced miRNA cDNA Synthesis Kit (AB Applied Biosystems) was used for the preparation of cDNA templates from the entire pool of mature miRNAs in each sample according to the manufacturer's instructions. cDNA template (miRNA reaction product) was diluted (1:10) and PCR reaction mix was prepared using PCR master mix and human miRNA-specific primers (Table 1) according to the number of samples. The diluted cDNA template for each sample was added to a 96-well PCR plate containing the PCR mix (Applied Biosystems) and Real-time PCR reactions were performed using 7500 Fast Real-Time PCR System (Applied Biosystems) with following conditions: $95^{\circ} \mathrm{C}$ for $10 \mathrm{~min}$, followed by 40 cycles of $95^{\circ} \mathrm{C}$ for $15 \mathrm{~s}$ and $60^{\circ} \mathrm{C}$ for $1 \mathrm{~min}$. All reactions were run in triplicate. The level of miRNA expression was measured using the threshold cycle (CT), miRNA PCR results (CT values) were normalised against the internal control miR-26b using $2^{-\Delta \Delta C t}$ method (Livak \& Schmittgen 2001).

\section{Follicle determination in ovarian cortical tissue}

PFA-fixed cortical tissues from all groups (fresh, freshcultured and cryopreserved-cultured) were processed, embedded in paraffin and sectioned into $5 \mu \mathrm{m}$ thin serial sections using a microtome (Leica). Approximately 100105 sections were made from each ovarian cortical tissue and stained using H\&E.

To estimate the number of ovarian follicles of the categories described below, slides that contained sections $50 \mu \mathrm{m}$ apart where selected, to avoid double-counting of follicles. Follicles were categorised according to the

Table 1 TaqMan probe choices and their corresponding mature miRNA sequence in humans (Griffiths-Jones et al. 2006).

\begin{tabular}{l}
\hline TaqMan probe \\
Human: has-miR-24-3p \\
Human: has-miR-193b-3p \\
Human: has-miR-320A \\
Human: has-miR-26b-3p
\end{tabular}

Mature human miRNA sequence UGGCUCAGUUCAGCAGGAACAG AACUGGCCCUCAAAGUCCCGCU AAAAGCUGGGUUGAGAGGGCGA CCUGUUCUCCAUUACUUGGCUC https://jme.bioscientifica.com

https://doi.org/10.1530/JME-18-0237
(C) 2019 Society for Endocrinology Published by Bioscientifica Ltd. Printed in Great Britain morphological appearance of GCs based on (Telfer et al. 2008) as follows: (1) primordial follicles, an oocyte surrounded by a few squamous GCs; (2) transitional follicles, an oocyte surrounded by squamous and at least one cuboidal GC; (3) primary follicle, an oocyte surrounded by a single layer of cuboidal GCs; (4) secondary follicle, an oocyte surrounded by two or more layers of cuboidal GCs and (5) early antral follicle (Telfer et al. 2008).

\section{Statistical analyses}

Data in this study were reported as means \pm s.e.m. unless otherwise specified. Obtained data were checked for normality using Kolmogorov-Smirnov/ShapiroWilk test and log transformed when necessary. Data were analysed using GenStat statistical software (v19; VSNi, UK). Repeated-measures ANOVA was used to compare miRNA expression, oestradiol, progesterone and androstenedione concentrations between freshcultured and cryopreserved-cultured groups. Follicle populations were not normally distributed and therefore transformed, compared between fresh, fresh-cultured and cryopreserved-cultured groups using two-way ANOVA and Tukey test. A $P$ value of $<0.05$ was considered statistically significant.

\section{Results}

\section{Ovarian steroidal production}

Throughout culture, as shown in Fig. 2, oestradiol production was significantly lower in cryopreservedcultured tissues compared to fresh-cultured tissues $(P<0.001$; Fig. 2). Despite, an increased observed in oestradiol in the spent culture media produced by fresh-cultured cortical tissue and an apparent decrease in cryopreservedcultured tissue from Day 1 to Day 5, day of culture was not significantly different $(P=0.894 ;$ Fig. 2$)$. There was statistically significant interaction between treatment and day of culture $(P=0.025)$, indicating that in fresh-cultured tissue, oestradiol concentrations increased in Days 4 and 5 , contrary to what occurred in cryopreserved-culture tissue.

Progesterone production was similar between freshcultured and cryopreserved-cultured groups during the initial 3 days in culture (Fig. 3). However, from Day 4, progesterone production decreased abruptly in cryopreserved-cultured tissues but increased in fresh-cultured tissue ( $P=0.02$; Fig. 3). Moreover, while progesterone concentrations seemed to increase throughout culture, those from cryopreserved-cultured 


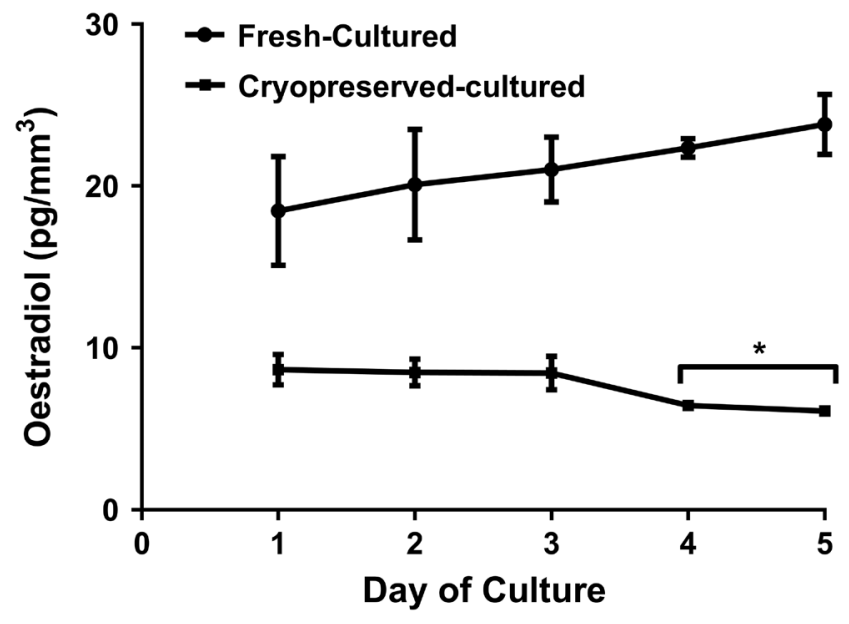

Figure 2

Oestradiol concentration (ng) per volume of tissue $\left(\mathrm{mm}^{3}\right)$ in the spent culture media for both fresh and cryopreserved cortical tissue, over 5 days of culture. Significant differences were noted in oestradiol concentrations between groups (fresh-cultured and cryopreservedcultured) $(P<0.001)$ and its interaction with culture day $(P=0.025$; indicated by *), but not in culture day within treatments $(P=0.894)$.

tissue decreased in Days 4 and 5 of culture $(P=0.013$ treatment $\times$ culture day; Fig. 3).

Concentrations of androstenedione in spent culture media between fresh-cultured and cryopreserved-cultured groups followed a similar pattern to those of progesterone (Fig. 4). Production of androstenedione was comparable between both groups during the initial 3 days of culture, but from Day 4 onward, while concentrations decrease in cryopreserved-cultured tissues, they reach maximal

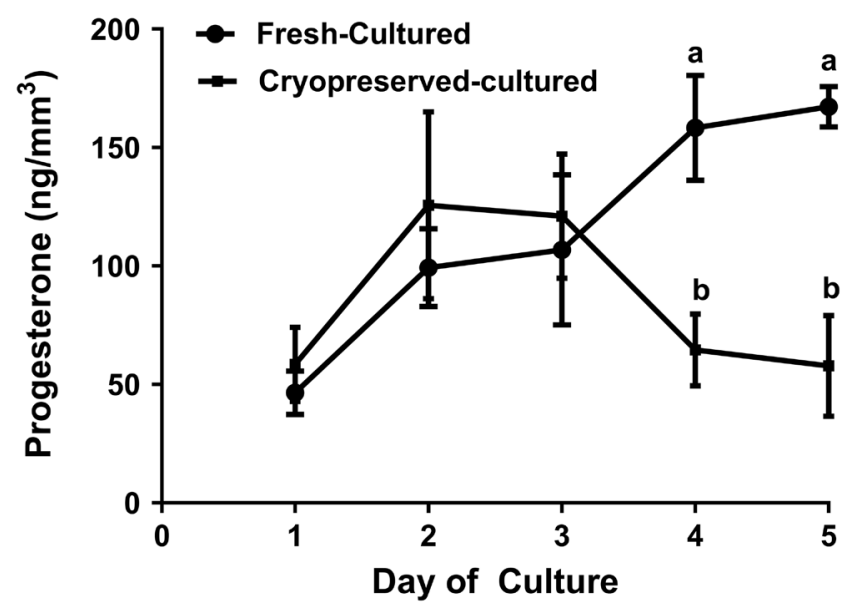

Figure 3

Progesterone concentration (ng) per volume of tissue $\left(\mathrm{mm}^{3}\right)$ in the spent culture media for both fresh and cryopreserved ovarian cortical tissue, over 5 days of culture. A significant difference was observed between treatments (fresh-cultured and cryopreserved-cultured; $P=0.02$ ), culture day $(P=0.02)$ and there was a signification interaction between these $(P=0.013)$. Different letters indicate these interaction $(P=0.013)$.

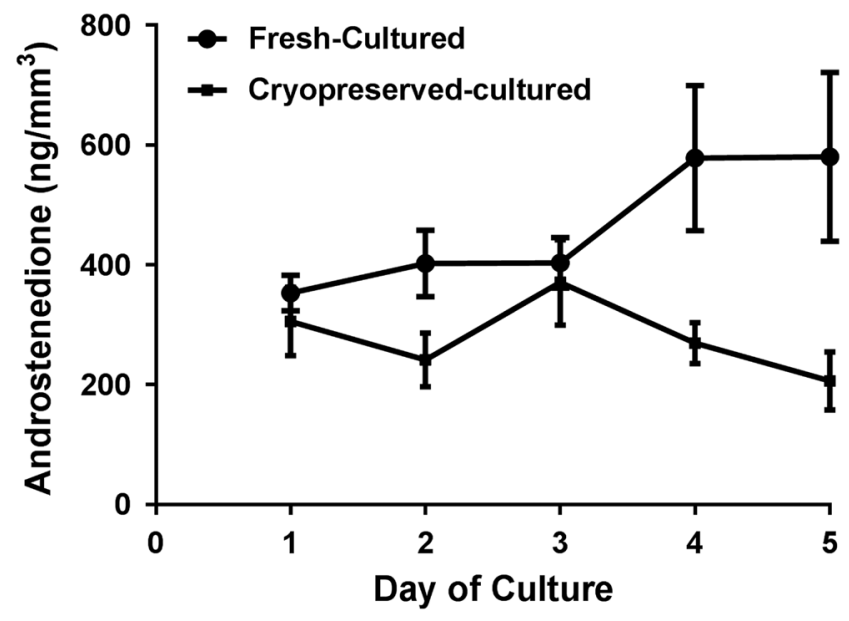

Figure 4

Androstenedione concentration (ng) per volume of tissue $\left(\mathrm{mm}^{3}\right)$ in the spent culture media for both fresh and cryopreserved cortical tissue, over 5 days of culture. A significant difference was observed between treatments (fresh- cultured and cryopreserved-cultured; $P<0.001$ ) but not between culture days $(P=0.646)$ nor was there an interaction between terms $(P=0.11)$.

production in fresh-cultured tissues $(P<0.001$; Fig. 4). However, within groups no differences were observed in androstenedione concentrations between different days of culture $(P=0.646)$.

\section{Expression of miRNAs}

Relative expression of miRNA-24 was higher in cryopreserved-cultured tissues throughout culture compared to fresh-cultured tissues $(P<0.001$; Fig. 5). However, relative expression of miRNA-24 in cryopreserved-cultured tissue increased from Day 1 to Day 2, but decrease on Days 3 and 4, and suddenly increased on Day 5 ( $P=0.031)$ (Fig. 5). For fresh-cultured tissues, relative expression of miRNA-24, decreased from Day 1 to Day 4 but increased on Day 5 ( $P=0.031$ ) (Fig. 5).

Relative expression of miRNA-193b in cryopreservedcultured tissue was detected on Day 1 (Fig. 6) but appeared to be downregulated (no detectable expression) in subsequent days $(P=0.043)$. Concentrations of miRNA-193b were higher in fresh-cultured compared to cryopreserved-cultured tissues on Day 1 (Day $1=58.4$, $P=0.004)$. However, expression in fresh culture decreased from 58.4 to 3.4 on Day 1 to Day 3, respectively, to then steadily increased to 7.6 on Day $5(P=0.043)$ (Fig. 6).

Relative expression of miR-320A showed higher expression on the first day in culture and then a decline on Day 2 with concentrations remaining constant there on $(P=0.001$; Fig. 7). However, expression levels of this 


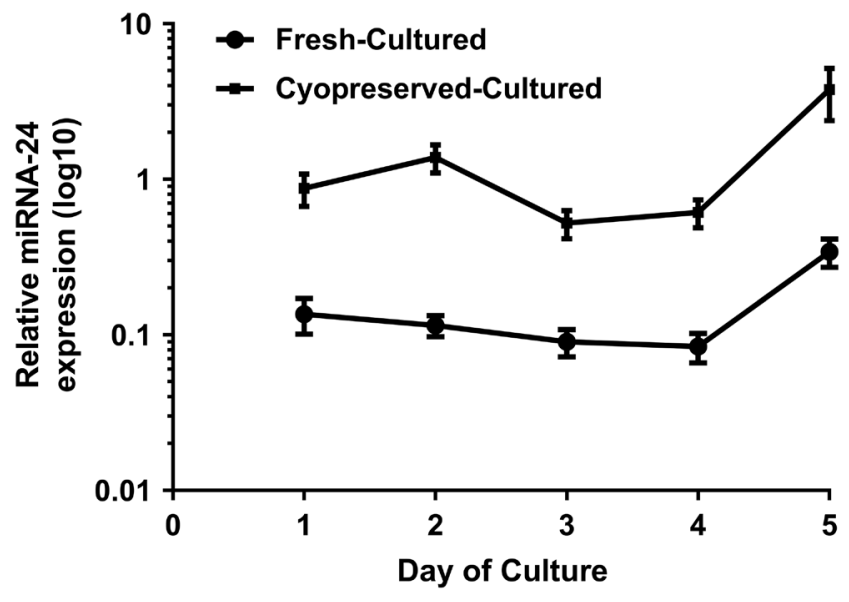

Figure 5

Log concentration of miRNA-24 relative to miRNA-26b, in the spent culture media of both fresh and cryopreserved cortical tissue, over 5 days of culture. A significant difference was noted in the expression of miRNA-24 between treatments (fresh-cultured and cryopreservedcultured $)(P<0.001)$ and culture day $(P=0.031$, with no significant interaction between these factors observed $(P=0.089))$.

miRNA were lower in cryopreserved-cultured tissue $(P=0.049)$ compared to tissues without freezing-thawing throughout culture (Fig. 7).

\section{Proportion of follicles in ovarian cortical tissue}

The proportion (percentage) of follicles present in a total of 24 ovarian cortical tissues section was histologically estimated: fresh ( $n=8$ sections); cryopreserved-cultured

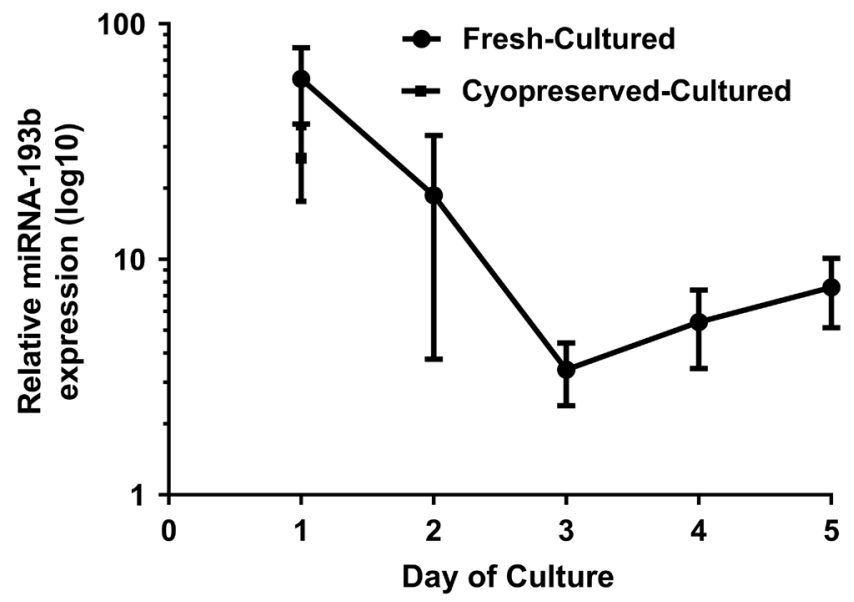

\section{Figure 6}

Log concentration of miRNA-193b relative to miRNA-26b, in spent media of both fresh and cryopreserved ovarian cortical tissue, over 5 days of culture. A significant difference was noted in the expression of miRNA193b between treatments (fresh-cultured and cryopreserved-cultured) $(P=0.004)$ and culture day $(P=0.043)$, with no significant interaction between these factors observed $(P>0.05)$.

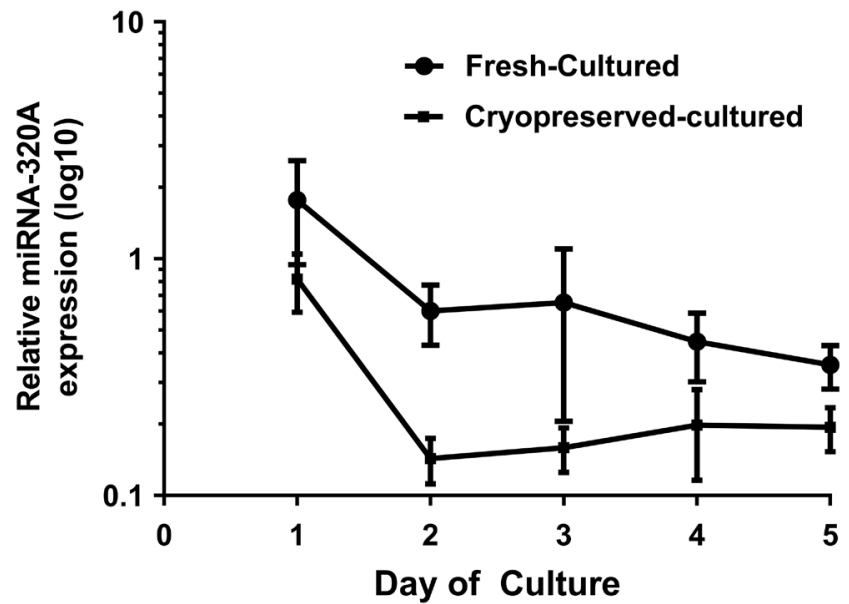

Figure 7

Log concentration of miRNA-320A relative to miRNA-26b, in spent media of both fresh and cryopreserved ovarian cortical tissue, over 5 days of culture. A significant difference was noted in the expression of miRNA320A between treatments (fresh-cultured and cryopreserved-cultured) $(P=0.049)$ and culture day $(P=0.001)$, with no significant interaction between these factors observed $(P=0.431)$.

( $n=8$ sections) and fresh-cultured ( $n=8$ sections). The number of primordial follicles decreased $(P<0.05)$ and late-stage follicles increased in fresh-cultured and cryopreserved-cultured groups compared to fresh cortical tissues (Table 2). Two-way ANOVA and Tukey test showed a significant difference between fresh and fresh-cultured cortical tissue for primordial $(P=0.0014)$, transitional $(P=0.0019)$ and secondary $(P=0.0027)$ follicles, fresh and cryopreserved-cultured cortical tissue of primordial $(P<0.001)$, transitional $(P=0.0018)$ and primary follicles $(P=0.0393)$, as well as fresh-cultured and cryopreservedcultured cortical tissue in case of primary $(P=0.0131)$ follicles (Table 2).

\section{Discussion}

Ovarian tissue cryopreservation was associated with a differential expression of the studied miRNAs and a reduction in steroidal hormone production. Furthermore, primordial follicle number decreased nearly 50 and $25 \%$ in cryopreserved-cultured and fresh-cultured tissues, respectively, compared to fresh tissues. To the best of the authors' knowledge, this is the first study to identify a possible correlation between cryopreservation, hormones (oestradiol, progesterone and androstenedione) and miRNAs' in spent culture media. The protocol used was successful at obtaining and measuring miRNAs' expression and oestradiol, progesterone and androstenedione in spent culture media, and thus, provides a novel noninvasive way to estimate tissue quality in culture. 
Table 2 Proportion (percentage) of follicles in fresh, fresh-cultured and cryopreserved-cultured cortical tissues.

\begin{tabular}{lcc}
\hline Cortical tissues & & Fresh \\
\cline { 1 - 2 } Total follicles & 884 \\
Primordial follicles & $76 \pm 4.2 \%(\mathrm{a})$ \\
Transitional follicles & $22.8 \pm 2.1 \%(\mathrm{~d})$ \\
Primary follicles & $7 \pm 1.3 \%(\mathrm{f})$ \\
Secondary follicles & $2.8 \pm 1.2 \%(\mathrm{~h})$ \\
Early antral follicles & $2.4 \pm 0.3 \%$ \\
\hline
\end{tabular}

\begin{tabular}{c}
\hline Fresh-cultured \\
\hline 779 \\
$45 \pm 4.6 \%$ (b) \\
$23.8 \pm 4.3 \%(\mathrm{c})$ \\
$8 \pm 1.4 \%(\mathrm{f})$ \\
$4 \pm 0.9 \%(\mathrm{~g})$ \\
$3 \pm 0.8 \%$ \\
\hline
\end{tabular}

Cryopreserved-cultured

526

$27.3 \pm 3.4 \%(b)$

$35.8 \pm 2.7 \%(c)$

$6 \pm 1.5 \%(\mathrm{e})$

$6.8 \pm 1.1 \%(g)$

$4.9 \pm 0.9$

Different letters indicate significant differences between fresh, fresh-cultured and cryopreserved-cultured groups within same follicle category $(P<0.05)$.

The elevated expression of miRNA-24 in spent culture media for cryopreserved-cultured tissues may be due to solution effect toxicity of CPA during slow freezing. On the other hand, for cortical tissues cultured without freezing and thawing, cells recover and more follicles have activated during the culture process, resulting in decreased expression of miRNA-24. However, toward the end of culture, cells and tissue damage may have caused elevated expression of miRNA-24. Interestingly, miRNA24 has also been described as a regulator of oestradiol concentration; increased miRNA-24 expression resulting in decreased transforming growth factor (TGF) signalling, and ultimately leading to inhibition of oestradiol secretion (Sang et al. 2013). Another recent study has shown that transfection with miRNA-24 mimics in the steroidogenic human granulosa-like tumour cell line, KGN, resulting in decreased oestradiol secretion (Sorensen et al. 2014). MiRNA-24 also regulates the genes of cellular survival pathway and is associated with reduced cellular viability (Manvati et al. 2015), also induce apoptosis and DNA damage in breast (Srivastava et al. 2011) and ovarian cancers (Sorensen et al. 2014, Manvati et al. 2015). Our findings support this inverse relationship between miRNA24 expression and oestradiol concentration measured over the 5 days of culture for fresh-cultured and cryopreservedcultured cortical tissue.

For fresh-cultured ovarian cortical tissues, relative expression of miRNA-193b in the spent culture media was detected throughout the culture period (Fig. 6), but expression showed a downward progression on days 1-3 followed by an increase in days $4-5$. This may be linked to initial adaptation to culture and to follicular survival, as shown by increased oestradiol production, followed by tissue damage during later culture stages. Contrary to the previous, expression of miR-193b was only detected on Day 1 in cryopreserved-cultured ovarian cortical tissue (Fig. 6). Abnormal downregulation of this miRNA is frequently observed in human disease (Sorensen et al. 2014) such as pancreatic cancers (Jin et al. 2015) and systemic sclerosis (Iwamoto et al. 2016). Reduced expression of miRNA-193b is also linked to increased expression of caspase-3, which is an important marker for cellular apoptosis (Wu et al. 2017). Therefore, changes in expression observed in this study support the role of miRNA-193b as apoptosis regulator.

The relative expression of miRNA-320A in spent culture media was detected on Day 1 in fresh-cultured and cryopreserved-cultured tissues, but higher in the former group (Fig. 7). As observed in Fig. 7 concentrations decreased in a similar pattern in both groups as culture progressed. MiRNA-320 expression has been previously reported in human follicular fluid (Feng et al. 2015) and along with miRNA-24, it is also involved in oestradiol regulation (Sang et al. 2013), with increased expression levels of miRNA-320A is linked to decrease in the level of oestradiol (Yin et al. 2014). Interestingly, a similar relationship is also observed in this study with oestradiol concentrations in spent media increasing in freshcultured tissue as expression of miRNA-320 decreased. Nonetheless, oestradiol levels in spent culture media remained low in spite of continuous low expression of miRNA-320A from cortical tissue undergoing cryopreservation and culture. Continuous low expression of miRNA-320 in case of cryopreserved-cultured tissues may be related to adverse cryopreservation effects resulting in increased cellular loss.

Previous work from our laboratory involving ovine ovarian cortical tissue culture in the RCCS showed improved survivability of the follicles compared to conventional methods. This vessel simulates the 3D environment in which tissue normally develops and functions (Barrila et al. 2010). Another advantage is waste materials around tissue are diluted with media due to periodic circulation of media flow (Morabito et al. 2015). This enabled the ovarian cortical tissue to secrete their miRNAs, steroid hormones and other substances into the culture media as close to what they normally would do in vivo. The ovarian cortical tissue cultured in a $3 \mathrm{D}$ culture vessel demonstrated a decrease in the number of primordial follicles and increase in the number of 
more developed follicle stages in fresh-cultured and cryopreserved-cultured tissue compared to fresh cortical tissue. Surgical sectioning of the cortical tissue, as well as tissue processing, may induce ischaemia which leads to the loss of primordial follicles (Campos et al. 2011). On the other hand, culture of ovarian cortical tissues in RCCS have increased activation of follicles which in turn have increased their number than the fresh cortical tissues.

Higher concentrations of steroid production were detected in cortical tissue during RCCS culture in later stages of fresh-cultured compared to cryopreservedcultured tissues (Figs 2, 3 and 4). Detection of these steroids in the spent culture media for both freshcultured and cryopreserved-cultured cortical tissue is an indication of steroidogenic function of the cortical tissue (Xu et al. 2011). Previous studies have also suggested that steroidogenic activity is maintained in the ovarian cortical tissue after cryopreservation by slow freezing (Campos et al. 2011). In this study, oestradiol and androstenedione were higher in fresh-cultured tissues which is consistent with aromatisation of androstenedione into oestradiol at these stages. Furthermore, progesterone concentrations were higher toward the end of culture in fresh-cultured tissues, which also indicates active steroidogenic pathways. Bastings et al. in 2014 reported a decline in the level of oestradiol and progesterone in the spent culture media from the cortical tissue undergoing freezing-thawing and culture for 7 days (Bastings et al. 2014). Loss of follicles of about $30-60 \%$ have been reported in various studies where ovarian cortical tissue has been frozen using slow freezing technique (Maltaris et al. 2006, Silber et al. 2010, Campos et al. 2011). Taking together, steroidal production indicates that fresh-cultured tissues were able to adapt better to the culture conditions and survive up to 5 days, with higher oestradiol, androstenedione and progesterone production compared to cryopreserved-cultured tissues.

For androstenedione production, there was a continuous downward progression in case of ovarian cortical tissue undergoing culture following freezingthawing apart from Day 3 where the concentration spiked suddenly, while cortical tissue cultured without freezing showed a steady increase. It is expected that androstenedione production would parallel the oestradiol production because it is largely a result of aromatisation of androgens by the enzyme aromatase (George \& Wilson 1978).

There were significant differences noted between miRNA expression pattern in spent culture media and follicle number for ovarian cortical tissues cultured with or without freezing. We therefore plan to investigate further the relationship between these miRNAs and follicle survivability, as well as elucidate into which specific cell types are expressing those miRNAs in our next study

In conclusion, downregulation of miRNA-193b and miRNA-320A along with upregulation of miRNA24 for cryopreserved ovarian cortical tissue cultured in RCCS might have a synergistic role in cell apoptosis and consequently reduced oestradiol and progesterone production. As those miRNA markers paralleled oestradiol and progesterone concentration production by the follicular GCs, it appears they are good indicators of apoptosis occurring within the granulosa compartment of follicles when cultured in RCCS. Thus, there appears to be an interplay between these miRNAs and oestradiol and progesterone production and these could be further explored as novel markers of cell injuries and/or damage following cryopreservation in RCCS.

\section{Declaration of interest}

The authors declare that there is no conflict of interest that could be perceived as prejudicing the impartiality of the research reported.

\section{Funding}

The work was supported by the University of Nottingham.

\section{Author contribution statement}

The original experiment was designed by N I and W E M. N I and U P S performed all the laboratory procedures. Data collection, analysis and interpretation were done by $\mathrm{N} \mathrm{I}$, whereas $\mathrm{W} E \mathrm{M}, \mathrm{J} \mathrm{H} \mathrm{M}$ and $\mathrm{P} \mathrm{M}$ made the critical evaluation and final data analysis approval. N I and W E M prepared the manuscript which all authors have read and approved.

\section{Acknowledgements}

Our sincere gratitude to laboratory technicians Mrs Anne Skinner and Nicky Baker, Child Health, Obstetrics and Gynaecology, University of Nottingham, for their enormous support during the whole work.

\section{References}

Abir R, Ben-Aharon I, Garor R, Yaniv I, Ash S, Stemmer SM, BenHaroush A, Freud E, Kravarusic D, Sapir O, et al. 2016 Cryopreservation of in vitro matured oocytes in addition to ovarian tissue freezing for fertility preservation in paediatric female cancer patients before and after cancer therapy. Human Reproduction $\mathbf{3 1}$ 750-762. (https://doi.org/10.1093/humrep/dew007)

Abir R, Fisch B, Fisher N, Samara N, Lerer-Serfaty G, Magen R, HermanEdelstein M, Ben-Haroush A, Stein A \& Orvieto R 2017 Erratum to: attempts to improve human ovarian transplantation outcomes of needle immersed vitrification and slow-freezing by host and graft treatments. Journal of Assisted Reproduction and Genetics 34 645-645.

Al-Azawi T, Tavukcuoglu S, Khaki AA \& Al Hasani S 2013 Cryopreservation of human oocytes, zygotes, embryos and 
blastocysts: A comparison study between slow freezing and ultra rapid (vitrification) methods. Middle East Fertility Society Journal 18 223-232. (https://doi.org/10.1016/j.mefs.2012.10.008)

Amorim CA, Curaba M, Van Langendonckt A, Dolmans MM \& Donnez J 2011 Vitrification as an alternative means of cryopreserving ovarian tissue. Reproductive Biomedicine Online 23 160-186. (https://doi. org/10.1016/j.rbmo.2011.04.005)

Baerwald AR, Adams GP \& Pierson RA 2012 Ovarian antral folliculogenesis during the human menstrual cycle: a review. Human Reproduction Update 18 73-91. (https://doi.org/10.1093/humupd/dmr039)

Barrila J, Radtke AL, Crabbe A, Sarker SF, Herbst-Kralovetz MM, Ott CM \& Nickerson CA 2010 Organotypic 3D cell culture models: using the rotating wall vessel to study host-pathogen interactions. Nature Reviews. Microbiology 8 791-801. (https://doi.org/10.1038/ nrmicro2423)

Bastings L, Liebenthron J, Westphal JR, Beerendonk CC, Van Der Ven H, Meinecke B, Montag M, Braat DD \& Peek R 2014 Efficacy of ovarian tissue cryopreservation in a major European center. Journal of Assisted Reproduction and Genetics 31 1003-1012. (https://doi. org/10.1007/s10815-014-0239-7)

Campbell BK, Scaramuzzi RJ \& Webb R 1996 Induction and maintenance of oestradiol and immunoreactive inhibin production with FSH by ovine granulosa cells cultured in serum-free media. Journal of Reproduction and Fertility 106 7-16. (https://doi. org/10.1530/jrf.0.1060007)

Campbell BK, Clinton M \& Webb R 2012 The role of anti-Mullerian hormone $(\mathrm{AMH})$ during follicle development in a monovulatory species (sheep). Endocrinology 153 4533-4543. (https://doi. org/10.1210/en.2012-1158)

Campos JR, Rosa-E-Silva JC, Carvalho BR, Vireque AA, Silva-De-Sá MF \& Rosa-E-Silva AC 2011 Cryopreservation time does not decrease follicular viability in ovarian tissue frozen for fertility preservation. Clinics 66 2093-2097. (https://doi.org/10.1590/S180759322011001200015)

Cortez MA, Bueso-Ramos C, Ferdin J, Lopez-Berestein G, Sood AK \& Calin GA 2011 MicroRNAs in body fluids--the mix of hormones and biomarkers. Nature Reviews. Clinical Oncology 8 467-477. (https://doi. org/10.1038/nrclinonc.2011.76)

Donnez J \& Dolmans MM 2017 Fertility preservation in women. New England Journal of Medicine 377 1657-1665. (https://doi.org/10.1056/ NEJMra1614676)

Donnez J, Dolmans MM, Pellicer A, Diaz-Garcia C, Ernst E, Macklon KT \& Andersen CY 2015 Fertility preservation for age-related fertility decline. Lancet 385 506-507. (https://doi.org/10.1016/S01406736(15)60198-2)

Feng R, Sang Q, Zhu Y, Fu W, Liu M, Xu Y, Shi H, Xu Y, Qu R, Chai R, et al. 2015 MiRNA-320 in the human follicular fluid is associated with embryo quality in vivo and affects mouse embryonic development in vitro. Scientific Reports 5 8689. (https://doi. org/10.1038/srep08689)

George FW \& Wilson JD 1978 Conversion of androgen to estrogen by the human fetal ovary. Journal of Clinical Endocrinology and Metabolism 47 550-555. (https://doi.org/10.1210/jcem-47-3-550)

Gosden RG, Baird DT, Wade JC \& Webb R 1994 Restoration of fertility to oophorectomized sheep by ovarian autografts stored at $-196^{\circ} \mathrm{C}$. Human Reproduction 9 597-603. (https://doi.org/10.1093/ oxfordjournals.humrep.a138556)

Griffiths-Jones S, Grocock RJ, van Dongen S, Bateman A \& Enright AJ 2006 miRBase:microRNA sequences, targets and gene nomenclature. Nucleic Acids Research 34 D140-D144. (https://doi.org/10.1093/nar/ gkj112)

Houbaviy HB, Murray MF \& Sharp PA 2003 Embryonic stem cell-specific microRNAs. Developmental Cell 5 351-358. (https://doi.org/10.1016/ S1534-5807(03)00227-2)

Iwamoto N, Vettori S, Maurer B, Brock M, Pachera E, Jungel A, Calcagni M, Gay RE, Whitfield ML, Distler JH, et al. 2016
Downregulation of miR-193b in systemic sclerosis regulates the proliferative vasculopathy by urokinase-type plasminogen activator expression. Annals of the Rheumatic Diseases 75 303-310. (https://doi. org/10.1136/annrheumdis-2014-205326)

Jin X, Sun Y, Yang H, Li J, Yu S, Chang X, Lu Z \& Chen J 2015 Deregulation of the MiR-193b-KRAS axis contributes to impaired cell growth in pancreatic cancer. PLOS ONE 10 e0125515. (https://doi. org/10.1371/journal.pone.0125515)

Livak KJ \& Schmittgen TD 2001 Analysis of relative gene expression data using real-time quantitative PCR and the 2(T)(-Delta Delta C) method. Methods 25 402-408. (https://doi.org/10.1006/ meth.2001.1262)

Maltaris T, Dragonas C, Hoffmann I, Mueller A, Beckmann MW \& Dittrich R 2006 Simple prediction of the survival of follicles in cryopreserved human ovarian tissue. Journal of Reproduction and Development 52 577-582. (https://doi.org/10.1262/jrd.18012)

Manvati S, Mangalhara KC, Kalaiarasan P, Srivastava N \& Bamezai RN 2015 miR-24-2 regulates genes in survival pathway and demonstrates potential in reducing cellular viability in combination with docetaxel. Gene 567 217-224. (https://doi.org/10.1016/j. gene.2015.05.003)

Morabito C, Steimberg N, Mazzoleni G, Guarnieri S, Fano-Illic G \& Mariggio MA 2015 RCCS bioreactor-based modelled microgravity induces significant changes on in vitro 3D neuroglial cell cultures. BioMed Research International 2015 754283. (https://doi. org/10.1155/2015/754283)

Mukherji S, Ebert MS, Zheng GX, Tsang JS, Sharp PA \& Van Oudenaarden A 2011 MicroRNAs can generate thresholds in target gene expression. Nature Genetics 43 854-859. (https://doi. org/10.1038/ng.905)

Rayner KJ \& Hennessy EJ 2013 Extracellular communication via microRNA: lipid particles have a new message. Journal of Lipid Research 54 1174-1181. (https://doi.org/10.1194/jlr.R034991)

Sang Q, Yao Z, Wang H, Feng R, Wang H, Zhao X, Xing Q, Jin L, He L, Wu L, et al. 2013 Identification of microRNAs in human follicular fluid: characterization of microRNAs that govern steroidogenesis in vitro and are associated with polycystic ovary syndrome in vivo. Journal of Clinical Endocrinology and Metabolism 98 3068-3079. (https://doi.org/10.1210/jc.2013-1715)

Silber S, Kagawa N, Kuwayama M \& Gosden R 2010 Duration of fertility after fresh and frozen ovary transplantation. Fertility and Sterility $\mathbf{9 4}$ 2191-2196. (https://doi.org/10.1016/j.fertnstert.2009.12.073)

Snyder J, Son AR, Hamid Q, Wu H \& Sun W 2016 Hetero-cellular prototyping by synchronized multi-material bioprinting for rotary cell culture system. Biofabrication 8 015002. (https://doi. org/10.1088/1758-5090/8/1/015002)

Sorensen AE, Wissing ML, Salo S, Englund AL \& Dalgaard LT 2014 MicroRNAs related to polycystic ovary syndrome (PCOS). Genes (Basel) 5 684-708. (https://doi.org/10.3390/genes5030684)

Srivastava N, Manvati S, Srivastava A, Pal R, Kalaiarasan P, Chattopadhyay S, Gochhait S, Dua R \& Bamezai RN 2011 miR-24-2 controls H2AFX expression regardless of gene copy number alteration and induces apoptosis by targeting antiapoptotic gene BCL-2: a potential for therapeutic intervention. Breast Cancer Research 13 R39. (https://doi.org/10.1186/bcr2861)

Telfer EE, Mclaughlin M, Ding C \& Thong KJ 2008 A two-step serumfree culture system supports development of human oocytes from primordial follicles in the presence of activin. Human Reproduction 23 1151-1158. (https://doi.org/10.1093/humrep/den070)

Toloubeydokhti T, Bukulmez O \& Chegini N 2008 Potential regulatory functions of microRNAs in the ovary. Seminars in Reproductive Medicine 26 469-478. (https://doi.org/10.1055/s-0028-1096127)

Weber JA, Baxter DH, Zhang S, Huang DY, Huang KH, Lee MJ, Galas DJ \& Wang K 2010 The microRNA spectrum in 12 body fluids. Clinical Chemistry 56 1733-1741. (https://doi.org/10.1373/ clinchem.2010.147405) 
Wu K, Zhao Z, Ma J, Chen J, Peng J, Yang S \& He Y 2017 Deregulation of miR-193b affects the growth of colon cancer cells via transforming growth factor-beta and regulation of the SMAD3 pathway. Oncology Letters 13 2557-2562. (https://doi.org/10.3892/ ol.2017.5763)

Xu S, Linher-Melville K, Yang BB, Wu D \& Li J 2011 Micro-RNA378 (miR-378) regulates ovarian estradiol production by targeting aromatase. Endocrinology 152 3941-3951. (https://doi.org/10.1210/ en.2011-1147)

Xu L, Yang BF \& Ai J 2013 MicroRNA transport: a new way in cell communication. Journal of Cellular Physiology 228 1713-1719. (https://doi.org/10.1002/jcp.24344)

Yang X, Zhou Y, Peng S, Wu L, Lin HY, Wang S \& Wang H 2012 Differentially expressed plasma microRNAs in premature ovarian failure patients and the potential regulatory function of mir-23a in granulosa cell apoptosis. Reproduction 144 235-244. (https://doi. org/10.1530/REP-11-0371)

Yin M, Wang X, Yao G, Lu M, Liang M, Sun Y \& Sun F 2014 Transactivation of micrornA-320 by microRNA-383 regulates granulosa cell functions by targeting E2F1 and SF-1 proteins. Journal of Biological Chemistry 289 18239-18257. (https://doi.org/10.1074/ jbc.M113.546044)

Zumbado M, Luzardo OP, Lara PC, Álvarez-León EE, Losada A, Apolinario R, Serra-Majem L \& Boada LD 2010 Insulin-like growth factor-I (IGF-I) serum concentrations in healthy children and adolescents: relationship to level of contamination by DDTderivative pesticides. Growth Hormone and IGF Research 20 63-67. (https://doi.org/10.1016/j.ghir.2009.07.003)

Received in final form 22 March 2019

Accepted 29 March 2019

Accepted Preprint published online 29 March 2019
(C) 2019 Society for Endocrinology Published by Bioscientifica Ltd. Printed in Great Britain 